\title{
Preparation of 1910s-phytate, an in-vivo radionuclide generator, for radiosynovectomy application
}

\author{
L. Moghaddam*1, A. Jalilian², N.Salek ${ }^{1}$, M. Jamre ${ }^{3}$
}

\begin{abstract}
AFFILIATIONS
${ }^{1}$ Nuclear Fuel Cycle School, Nuclear Science and Technology Research Institute (NSTRI), 14155-1339 Tehran, Iran ${ }^{2}$ Radioisotope Products and Radiation Technology Section, Department of Nuclear Sciences and Applications, International Atomic Energy Agency (IAEA), Vienna, Austria

${ }^{3}$ Faculty of Nuclear Engineering and Physics, Amirkabir University of Technology, Tehran, Iran
\end{abstract}

* Author to whom correspondence should be addressed: Imoghaddam@aut.ac.ir

\begin{abstract}
191Os is a parent radionuclide with a $15.4 \mathrm{~d}$ half-life. It decays by beta emission to $191 \mathrm{mIr}$, which is a radionuclide with a 4.96s half-life. It decays by the isomeric transition to stable $191 \mathrm{Ir}$, emitting a $129-\mathrm{keV}$ gamma photon. In this study, 1910s-phytate was developed into an in-vivo radionuclide generator for simultaneous radiosynovectomy and imaging. 1910s-hexachloroosmate was used to prepare 191Os-phytate $(100 \mu \mathrm{Ci} / 50 \mu \mathrm{l})$ using reaction condition optimization followed by an intraarticular injection to rat knee joints. Also, its distribution and stability were assessed. The imaging of 191Os cation and 191Os-phytate was performed by SPCET. The 191Os-phytate complex was obtained at $\mathrm{pH}=5.5$ with normal saline at room temperature. Radio-TLC showed an overall radiochemical yield of $95-98 \%$. The complex was injected into the rats' knees, and the whole injected dose remained at the injection site even three days after injection. Due to the stability and retention of the complex in joints approved by biodistribution and imaging studies, the complex is a potential in vivo generator for cavital radiosynovectomy of minor joints.
\end{abstract}

Keywords: Radiosynovectomy, Phytate, Osmium-191, Biodistribution, Imaging

\section{INTRODUCTION}

Radiosynovectomy (RSV) has been proposed as a potent palliative therapy around the world for the last two decades [1] and several radiopharmaceuticals have been developed and used in $\mathrm{RSV}$, including 166Ho-macroaggregates [2] and Ho-166 phytate complex [3]. Phytate is the salt form of phytic acid (Fig.1). It is known that hexaphosphoric acid of inositol (Phytic Acid) is active in the absorption of calcium and phosphorous by the body and soluble in water in the form of sodium salt. However, it forms insoluble complexes with other metals such as $\mathrm{Ca}$, $\mathrm{Fe}$, and $\mathrm{Zn}$. In the blood, phytic acid binds with calcium ions forming colloidal particles captured by the reticuloendothelial system, principally by Kupffer cells in the liver [4]. The intravenous administration of $99 \mathrm{mTc}$-Phytate is used for hepatic gamma scintigraphy. It retains its capacity to react in vivo with calcium ions in the bloodforming $99 \mathrm{mTc}$-phytate, a colloid engulfed by the 
reticuloendothelial system's cells, allowing the organ to be easily visualized. However, it is also possible to observe the spleen and bone marrow [5]. Many phytate complexes labeled with betaemitters such as $166 \mathrm{Ho}$ [6], ${ }^{188-186} \mathrm{Re}$ [7], and ${ }^{169} \mathrm{Er}$ [7] have been developed for radiosynovectomy (RSV). 191Os $(\mathrm{E} \beta-\max =313 \mathrm{keV}, \mathrm{T} 1 / 2=15.4$ d), (Fig. 2), is one of the potential radionuclides for developing therapeutic radiopharmaceuticals usually prepared for $1910 \mathrm{~s} / 191 \mathrm{mIr}$ generator production.

$1910 \mathrm{~s} / 191 \mathrm{mIr}$ generator is suitable for the firstpass radionuclide angio-cardiography developed to prepare repeated delusions of 4.96-sec $191 \mathrm{~m} \mathrm{Ir}$ from its 15.4-day 1910s parent for injection [8]. Recently, potential therapeutic tumor-avid 191Oslabeled bleomycin has been developed for ultimate therapeutic evaluation [9].

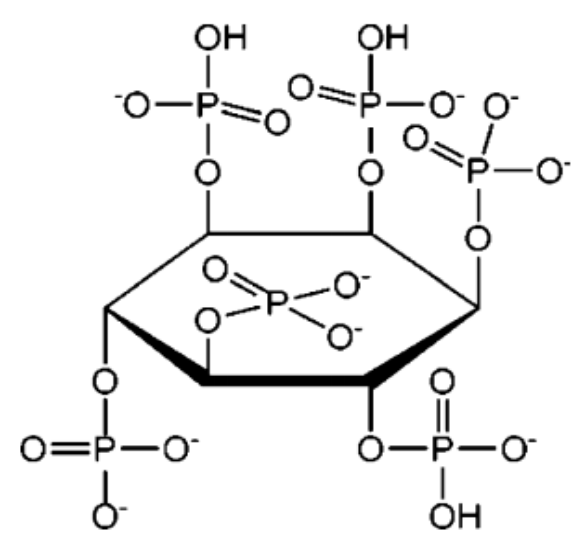

Fig. 1. Chemical formula for phytate

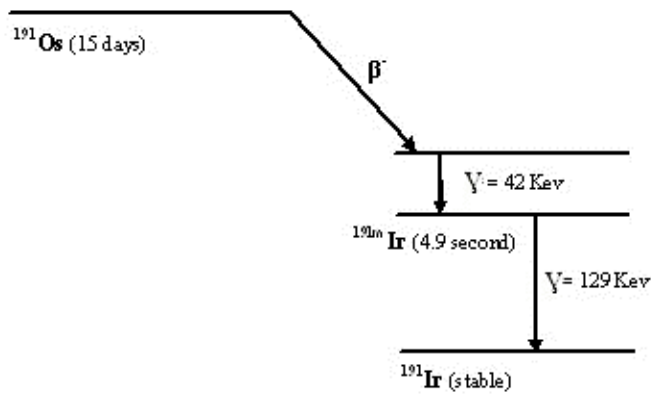

Fig. 2. Salient characteristics of osmium-191 decay
Due to the potential characteristics of 191Os as a beta emitter and phytate complex applications for radiosynovectomy, in this research, 191Os-phytate complex production is described in detail, followed by the determination of difficult radiochemical purity, stability, and bio-distribution (after intravenous and intraarticular injection) in wildtype rats.

\section{MATERIALS AND METHODS}

Isotopically enriched granulated metallic Osmium with a purity of $>90 \%$ was obtained from commercial vendors. Phytate complex was prepared using a commercial phytate kit (Pars Isotope Co., Tehran, Iran, stannous chloride free). Chromatography paper, Whatman No. 2, was obtained from Whatman (Maidstone, UK). Radiochromatography was performed using a BioScan AR-2000 radio TLC scanner instrument (Bioscan, Washington, DC, USA). A high purity germanium (HPGe) detector coupled with a Canberra ${ }^{\mathrm{TM}}$ (model GC1020-7500SL) multichannel analyzer and a dose calibrator ISOMED 1010 (Dresden, Germany) were used for counting distributed activity in rat organs. All other chemical reagents were purchased from Merck (Darmstadt, Germany). All values were expressed as mean \pm standard deviation (Mean \pm SD) and the data were compared using the student T-test. Statistical significance was defined as $\mathrm{P}<0.05$. Animal studies were performed following the United Kingdom Biological Council's Guidelines on the Use of Living Animals in Scientific Investigations, 2nd ed. All of the rats were purchased from Pasteur Institute of Iran, weighing 180-220 $\mathrm{g}(\mathrm{n}=5)$ and were kept at routine day/night light program, and were kept under standard rodent diet pellets. 


\section{A. Osmium-191 Production}

${ }^{191}$ Os was prepared by neutron irradiation of isotopically enriched $(90 \%)$ granulated metallic ${ }^{190} \mathrm{Os}$ in the Research Reactor of Tehran with subsequent fusion in a mixture of $\mathrm{KOH}-\mathrm{KNO}_{3}$ [10]. After fusion, the irradiated target is dissolved in water to give a $0.4 \mathrm{~N} \mathrm{KOH}$ solution of potassium perosmate (VIII), $\mathrm{K}_{2}\left[\mathrm{OsO}_{4}(\mathrm{OH})_{4}\right]$ (Fig. 3), which is mixed with two volumes of ethanol to reduce the Os (VIII) to Os (VI). After 10 minutes, five volumes of concentrated hydrochloric acid are added quickly, and the solution is heated in a boiling water bath for 30 minutes. The solution is then evaporated to dryness and the brick-red precipitate of $\mathrm{K}_{2} \mathrm{OsCl}_{6}$ dissolved in $0.9 \% \mathrm{NaCl}$ $0.01 \mathrm{~N} \mathrm{HCl}[11]$.

\section{B. Labeling of Phytate}

The ${ }^{191} \mathrm{Os}-\mathrm{K}_{2} \mathrm{OsCl}_{6}$ solution in a $2 \mathrm{ml}$ vial with 0.7 $2.2 \mathrm{mCi}$ activity was adjusted to $\mathrm{pH}=1$ by $\mathrm{HCl} 1 \mathrm{M}$ and $\mathrm{NaOH} 1 \mathrm{M}$. The vial solution was added to the kit vial containing $10 \mathrm{mg}$ sodium phytate (commercial phytate kit, Parsisotope Co., Tehran, Iran). The complex $\mathrm{pH}$ was adjusted to the $\mathrm{pH}=5.5$ in normal saline and was shaken for $10 \mathrm{~min}$ at room temperature. ITLC checked the radiochemical purity of the kit. For measuring radiochemical purity and radiolabeling yield, a $5 \mu 1$ of the sample of the ${ }^{191}$ Os-Phytate was spotted on Whatman No. 2 chromatography paper and developed in a mixture of $10 \mathrm{mM}$ DTPA solution as a mobile phase to discriminate free Osmium from the radiolabeled compound.

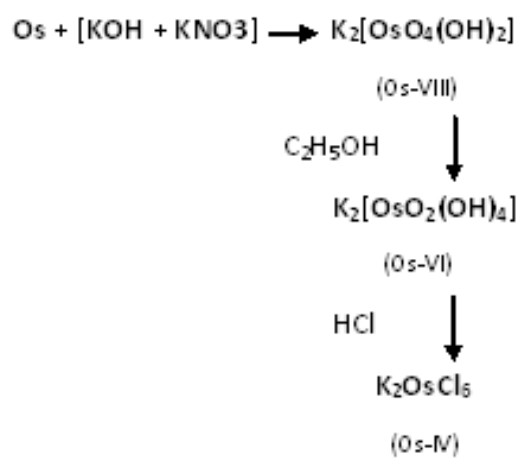

Fig. 3. Preparation of $\mathrm{K}_{2} \mathrm{OsCl}_{6}$

\section{Stability of ${ }^{191}$ Os-Pytate Complex in the Final Product}

A sample of ${ }^{191}$ Os-Phytate (18-180 MBq) was kept at room temperature for $48 \mathrm{~h}$ while checked by ITLC every $2 \mathrm{~h}$. A micropipette sample $(5 \mu \mathrm{L})$ was taken from the shaking mixture and the ratio of free radio-osmium to ${ }^{191}$ Os-Phytate was checked by ITLC in a mixture of $10 \mathrm{mM}$ DTPA solution as a mobile phase to discriminate free Osmium from the radiolabeled compound. A sample of ${ }^{191}$ Os-phytate was kept at room temperature for $24 \mathrm{~h}$ while checked by RTLC at time intervals $5 \mathrm{~min}, 2 \mathrm{~h}, 4 \mathrm{~h}$, and $24 \mathrm{~h}$.

\section{Bio Distribution}

To determine the accumulation of ${ }^{191} \mathrm{Os}-\mathrm{K}_{2} \mathrm{OsCl}_{6}$ and ${ }^{191}$ Os-Phytate in the intraarticular cavity as well as after intravenous injection, the isotonic solution was carefully administered to wild-type rats of $200 \mathrm{~g}$ average weight each. A volume $(50 \mu \mathrm{l})$ of the final radiolabeled solution containing 100 $\mu \mathrm{Ci}$ radioactivity was injected intraarticularly to rats. 5 groups were killed 30min, $4 \mathrm{~h}, 24 \mathrm{~h}$, and $72 \mathrm{~h}$ after injection of the radio-pharmaceutical. Samples of 13 organs including blood, liver, lung, heart, muscle (related to injected knee), spleen, stomach, kidney, thyroid, intestine, injected knee, uninjected knee, and tail were excised, weighed wet, and counted by NaI (Tl) well counter. The absolute tissue concentrations were expressed as a percentage of the administered dose per gram of the wet tissue.

\section{E. Spec Imaging of ${ }^{191} \mathrm{Os}-\mathrm{K}_{2} \mathrm{OsCl} \mathrm{Cl}_{6}$ and ${ }^{191}$ Os-Phytate in Wild-type Rats \\ ${ }^{191} \mathrm{Os}-\mathrm{K}_{2} \mathrm{OsCl}_{6}$ and ${ }^{191}$ Os-phytate solutions in} appropriate buffers were injected $(50 \mu \mathrm{Ci}$ to each rat) intravenously through its tail vein. The images were taken at 24,48 , and 72 hours (for ${ }^{191}$ Os- 
$\mathrm{K}_{2} \mathrm{OsCl}_{6}$ ) and $4 \mathrm{~h}, 24,48$, and 72 hours (for ${ }^{191} \mathrm{Os-}$ phytate) after administration of the labeled compound by a single head gamma camera. The distance of rat to high energy septa was $12 \mathrm{~cm}$. The useful field of view (UFOV) was $540 \mathrm{~mm} \times 400$ $\mathrm{mm}$. The spatial resolution was $10 \mathrm{~mm}$ FWHM at the CFOV. Sixty-four projections were acquired for 30 seconds per view with a $64 \times 64$ matrix.

\section{RESULTS AND DISCUSSION}

\section{A. Radionuclide Purity}

The radionuclide purity was obtained by counting the samples on an HPGe detector (Gamma 2000\spectralSPCANL 17790.dat) for $2 \mathrm{~h}$, and two major photons (129.27 keV and $64.96 \mathrm{keV})$ were observed (Fig. 4). The $129.27 \mathrm{keV}$ is assigned to ${ }^{191 \mathrm{~m}} \mathrm{Ir}$ decay and $64.96 \mathrm{keV}$ is assigned to $\mathrm{x}$-ray emission of ${ }^{191}$ Os.

\section{B. Labeling}

The radiochemical yields were determined by ITLC. At optimized condition, total labeling and formulation of ${ }^{191}$ Os-Phytate took about $24 \mathrm{~h}$, with a yield of $>98 \%$. The radiolabeled complex was stable in an aqueous solution for at least $72 \mathrm{~h}$ and no significant amount of other radioactive species was detected by ITLC. The trace amount of ${ }^{191}$ Os$\mathrm{K}_{2} \mathrm{OsCl}_{6}(\approx 2 \%)$ was detected by RTLC which showed that radiochemical purity of the ${ }^{191}$ OsPhytate was higher than $97 \%$ (Figures 5, 6).

Radiochemical impurities in the ${ }^{191} \mathrm{Os}-\mathrm{K}_{2} \mathrm{OsCl}_{6}$ sample used in the radiolabeling step were checked by a $10 \mathrm{mM}$ DTPA solution as a mobile phase on Whatman No.2 paper (pH.3). The ${ }^{191} \mathrm{Os}-\mathrm{K}_{2} \mathrm{OsCl}_{6}$ cation in ${ }^{191} \mathrm{Os}^{4+}$ form was chelated with the polydentate eluting leading to the migration of the cation in ${ }^{191}$ Os-DTPA form to higher $\mathrm{R}_{\mathrm{f}}\left(\mathrm{R}_{\mathrm{f} .} .0 .8\right)$. Any other ionic species would lead to the observation of new radiopeaks, especially at the origin ( $\mathrm{R}_{\mathrm{f} .0 .02-0.05)}$ (Figure 5).

Because of the relatively high molecular weight of the colloid formed by the phytate monomers at the reaction $\mathrm{pH}$, the phytate complex remains at the origin of ITLC $\left(\mathrm{R}_{\mathrm{f}} 0.0\right)$ (Figure 6.).

In order to obtain the highest specific activity in the shortest possible time, a quantitative study was designed using different amounts of phytate for a specific amount of radioactivity $\left(5 \mathrm{mCi}\right.$ of ${ }^{191} \mathrm{Os}$ for instance) while $25^{\circ} \mathrm{C}$ was a considered suitable temperature (Table 1.). A satisfactory labeling yield of $94-98 \%$ was obtained at room temperature using $10 \mathrm{mg}$ of phytate.

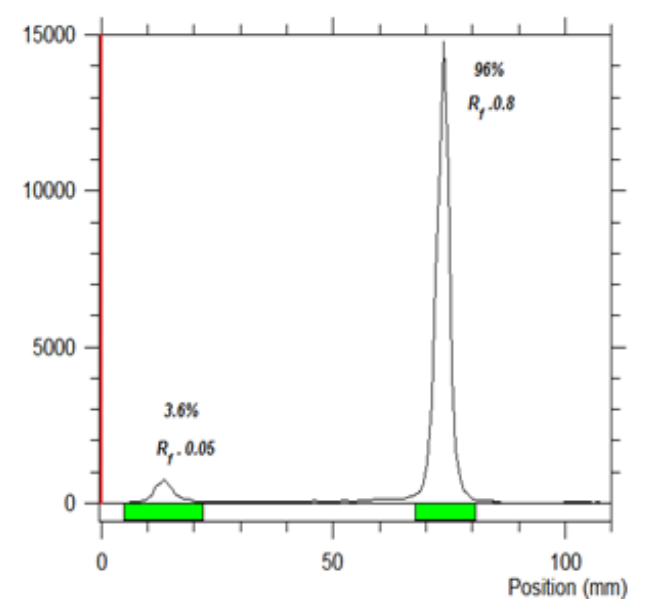

Fig. 5. Radiochoromatograph diagram of ${ }^{191} \mathrm{Os}-\mathrm{K}_{2} \mathrm{OsCl}{ }_{6}$

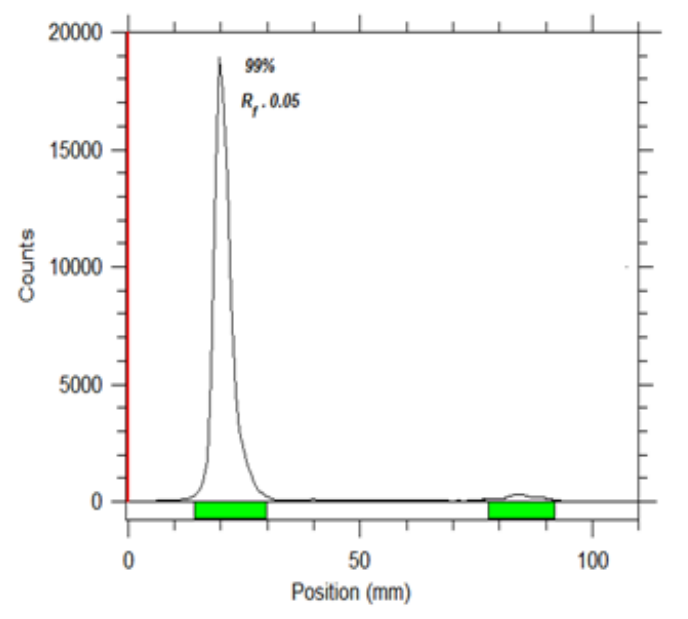

Fig. 6. Radiochoromatograph diagram of ${ }^{191}$ Os-Phytate 


\section{Table 1}

Percentages of Radiochemical Species in Radiolabeling Mixture Using Various Amounts of Sodium Phytate, 30 $\min , 25^{\circ} \mathrm{C}$ and $5 \mathrm{mCi}$ of ${ }^{191} \mathrm{Os}(\mathrm{n}=3)$

\begin{tabular}{cccc}
\hline Reaction & $\begin{array}{c}\text { 191 Os - } \\
\text { phytate (\%) }\end{array}$ & $\begin{array}{c}\text { 191 Os- } \\
\mathbf{K}_{2} \text { OsCl6 } \\
(\%)\end{array}$ & $\begin{array}{c}\text { Sodium } \\
\text { phytate } \\
(\mathbf{m g})\end{array}$ \\
\hline 1 & $84 \pm 2$ & $16 \pm 1.4$ & 2.5 \\
2 & $93 \pm 1$ & $7 \pm 1.1$ & 5 \\
3 & $>98$ & $<2$ & 10
\end{tabular}

\section{Biodistribution for free Os Cation}

In order to investigate the biodistribution of ${ }^{191} \mathrm{Os}-$ phytate in wild-type rats, we had to obtain the biodistribution data for free osmium cation for 4$72 \mathrm{~h}$ post-injection. The biodistribution of the cation was checked in various vital organs. The average percent dose per unit weight $\left(\% \mathrm{ID} \mathrm{g}^{-1}\right)$ of selected tissues from ${ }^{191} \mathrm{Os}-\mathrm{K}_{2} \mathrm{OsCl}_{6}$ is demonstrated in Fig. 7. The liver uptake of Osmium is higher than other organs and final liver delivery looks like the possible route of accumulation.

For free ${ }^{191}$ Os the radioactivity was mainly located in the heart, lung, liver, spleen, and kidney as previously shown by other researchers [12]. Heart uptake is naturally related to myocardial uptake as the daughter has been widely used as an angiographic agent in cardiology. Due to the resemblance of the Os cations especially at higher oxidation states to iodine anion, thyroid uptake was observed as shown in figure7 and this biokinetics was also shown for pertechnetate anion due to the charge/size resemblance. Also, as a free metallic cation, Osmium is carried through the circulation in protein-bound form and finally is accumulated in the liver. On the other hand, the water solubility, as well as negatively charge complex cation, is excreted through kidneys too.

\section{Biodistribution After Intra-articular}

\section{Administration ${ }^{191}$ Os-Phytate}

Figure 8 represents the distribution of the knee injected dose in the rats' organs at various time intervals after injection of $100 \mu \mathrm{Ci} / 50 \mu \mathrm{l}$ of the ${ }^{191}$ Os-phytate complex as a percentage of injected dose. In case of any leak from the joint, the complex would accumulate in the reticuluendothelial (RE) system because of the high molecular weight of the complex, unless the complex dissociated at serum $\mathrm{pH}$ and $\mathrm{Os}$ cation was formed. Almost no detectable amounts of activity were observed in the spleen and lung, which are two important organs, showing no complex leak occurred. Very negligible kidney uptakes were observed, which was possibly caused by ${ }^{191}$ Os cation release from the injected joint and not the radiolabeled complex uptake. Figure 9 demonstrates the biodistribution of the compound among the tissues excluding the injected knee data in order to better understand the biodistribution of the leaks from the knee. The distribution of the radioactivity among tissues after removing knee joint accumulation data demonstrated a typical Osmium cation biodistribution among the tissues. It is believed that free Osmium cation is the only radiochemical species escaping from the knee joint, and no ${ }^{191}$ Os-phytate complex was found in circulation. 


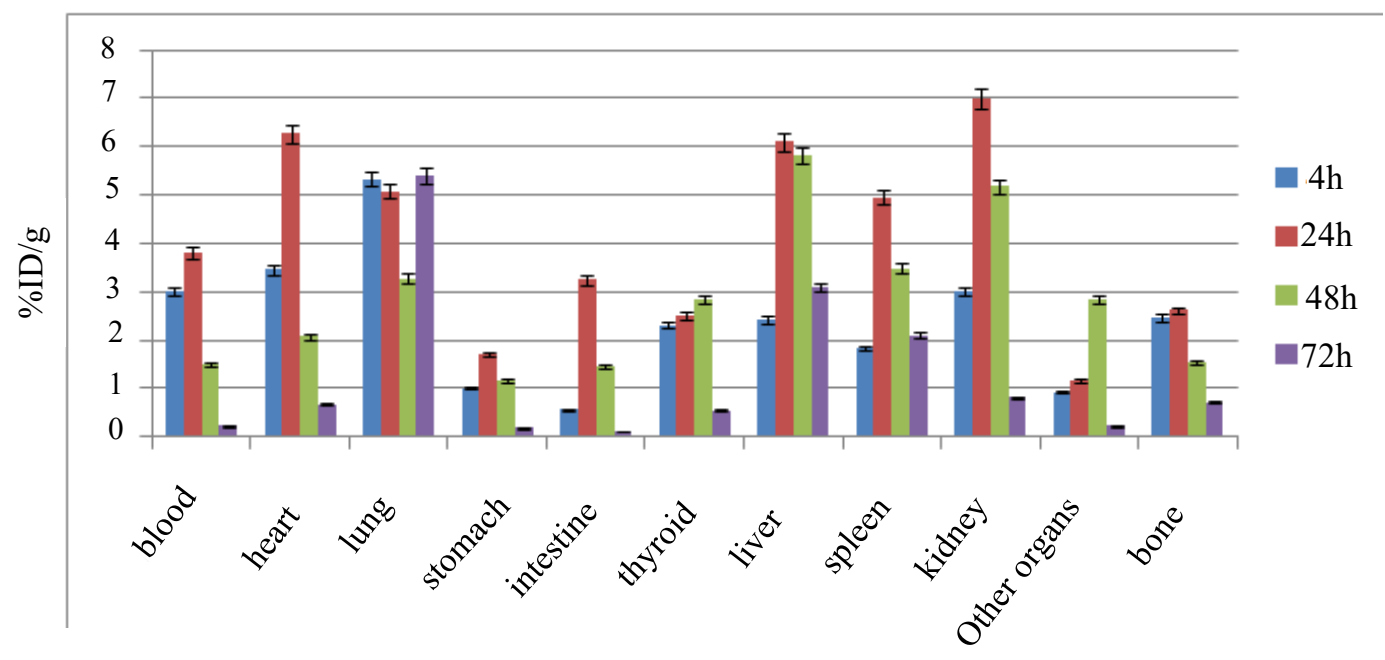

Fig. 7. Percentage of injected dose per gram of $\mathrm{K}_{2} \mathrm{OsCl}_{6}$ in wild-type rat tissues at $4,24,48,72 \mathrm{~h}$ post injection $(\mathrm{n}=3)$.

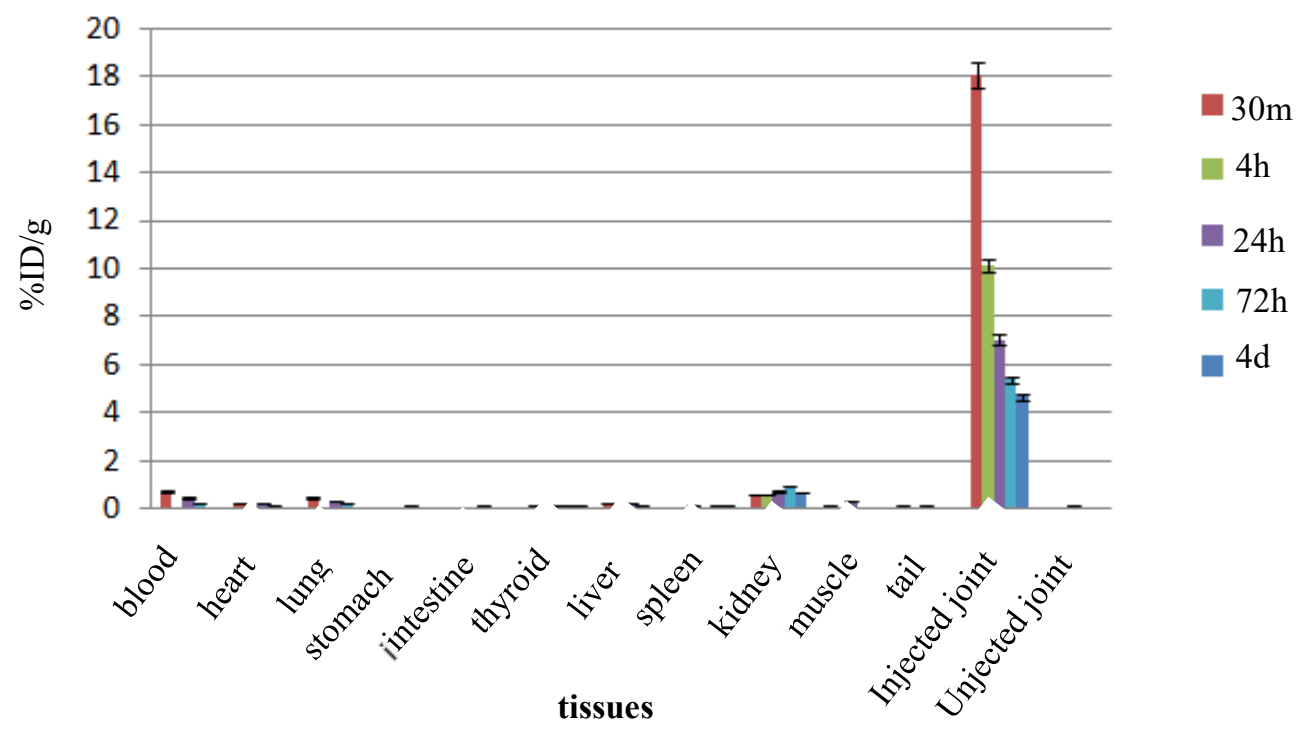

Fig. 8. Distribution of ${ }^{191}$ Os-phytate in wild-type rats, $0.5,4,24,72 \mathrm{~h}$ and $14 \mathrm{~d}$ after intraarticular injection $(\mathrm{n}=3)$

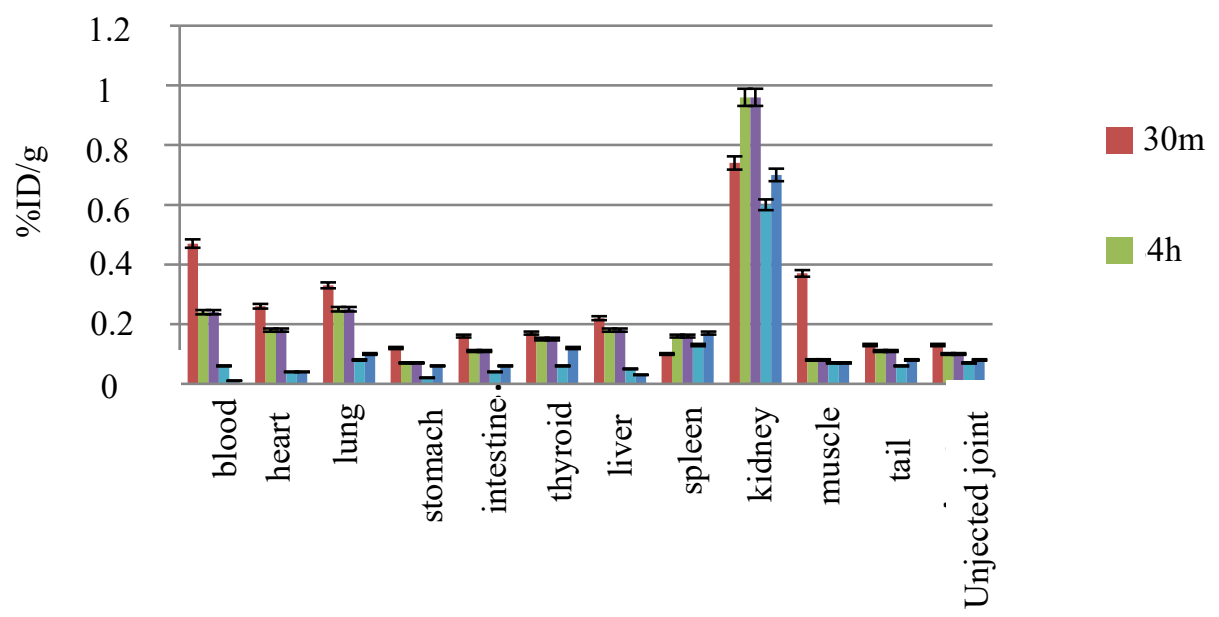

Fig. 9. Distribution of ${ }^{191}$ Os-Phytate in wild-type rats excluding injected knee data at $0.5,4,24,72 \mathrm{~h}$ and $14 \mathrm{~d}$ after injection $(n=3)$ 


\section{E. Imaging Studies}

Due to the decay of ${ }^{191}$ Os to the daughter gamma emitter $\left({ }^{191 \mathrm{~m}} \mathrm{Ir}\right)$, an in vivo generator is formed after a colloidal accumulation of the formulation giving imaging opportunity for detecting the injection site activity. For the imaging studies of the free cation and the labeled compound wild type rats were used. In $24 \mathrm{~h}$ free cation is majorly found in the heart while after $48 \mathrm{~h}$ most the activity is excreted through the kidneys showing high activity in the bladder. After $72 \mathrm{~h}$ most of the acidity is removed from the body, this is in accordance with other reported studies of the free cation in animals and humans (Figure 10).

Figure 11 shows images of ${ }^{191}$ Os-phytate incidence in wild-type rats $4,24,48$, and $72 \mathrm{~h}$ after knee intra-articular injection. Also, as already shown by dissection studies, the complex is majorly accumulated at the injection site and no detectable leaks observed after $72 \mathrm{~h}$ post intraarticular injection.

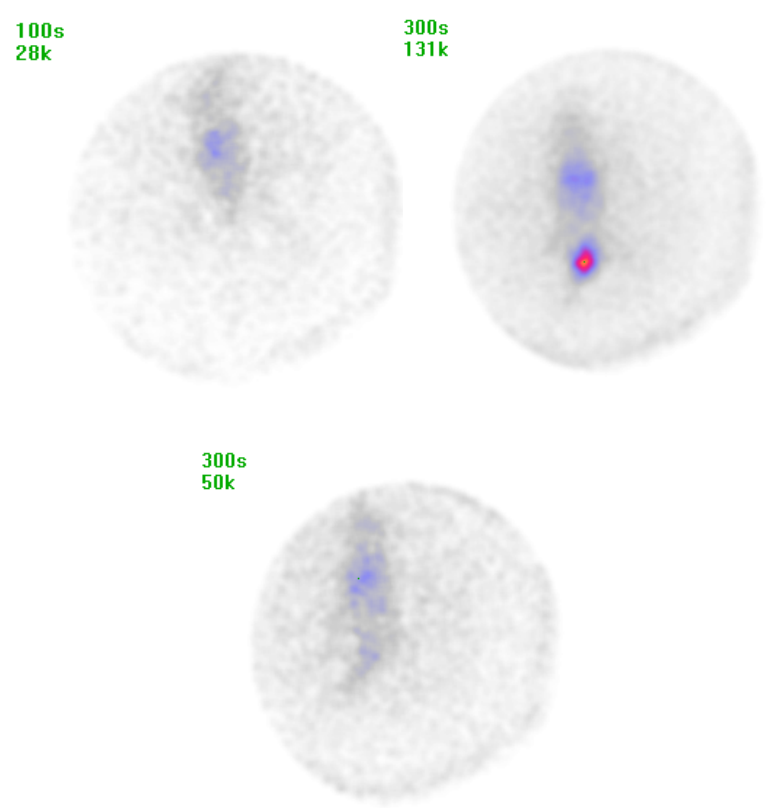

Fig. 10. Incidence images for $\left[{ }^{191} \mathrm{Os}\right] \mathrm{K}_{2} \mathrm{OsCl}_{6}$ uptake in normal rats, 24,48 and $72 \mathrm{~h}$ (from left to right) post i.e., injection.

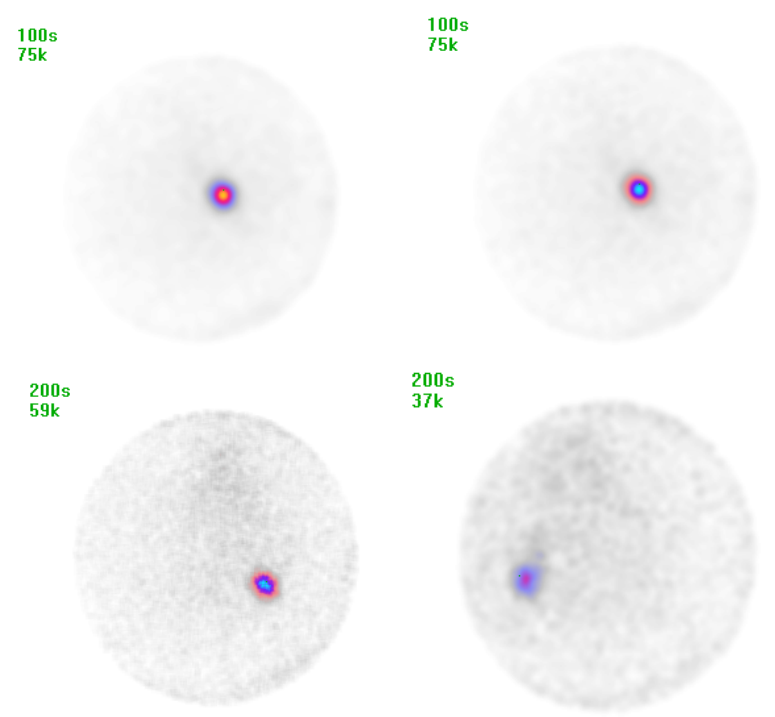

Fig. 11. ${ }^{191}$ Os-phytate incidence images in wild-type rats 4, 24, 48 and $72 \mathrm{~h}$ (from left to right) after knee intraarticular injection.

\section{CONCLUSION}

The ${ }^{191}$ Os-Phytate complex was prepared with a high radiochemical yield ( $>98 \%$ ) in the optimized condition, the prepared complex was stable in the final solution at room temperature, $37^{\circ} \mathrm{C}$, and presence of human serum, and can be used even 72 $\mathrm{h}$ after preparation. Intraarticular injection of the ${ }^{191}$ Os-Phytate complex to male wild-type rats and investigation of leakage of activity in the body showed that most of the injected dose remained in the injection site $72 \mathrm{~h}$ after Injection. Due to the decay of ${ }^{191} \mathrm{Os}$ to the daughter gamma emitter ( $\left.{ }^{191} \mathrm{Ir}\right)$, an in vivo generator is formed after the colloidal accumulation of the formulation giving imaging opportunity for detecting the injection site activity.

The rationale for using ${ }^{191}$ Os for the possible radiosynovectomy studies is coming from its high similarities to the physical characteristics of ${ }^{169} \mathrm{Er}$. Erbium-169, a soft beta-emitter (half-life 9.5 days, maximum energy $034 \mathrm{MeV}$ ) has been long used in the radiosynovectomy of carpal and metacarpal joints since the late 1970s and has been accepted 
for trials by the European Society of Nuclear Medicine [1].

Unfortunately, ${ }^{169} \mathrm{Er}$ is produced in research reactors at high prices due to the use of the enriched ${ }^{168} \mathrm{Er}$ material giving a high final price for most countries even in EU states. On the other hand, the aging population of the world is increasing with arthritis as well as related problems giving more demand to the less expensive radiosynovectomy agents. The search for new radionuclides with soft beta emission is a vital part of the radionuclide/radiopharmacy field.

According to Table $2{ }^{191}$ Os is also a soft beta emitter $(0.37 \mathrm{MeV})$ and the half-life is comparable to the ${ }^{168} \mathrm{Er}$. The maximum beta energies are very close $\left(0.34\right.$ and 0.37 for ${ }^{169} \mathrm{Er}$ and ${ }^{191} \mathrm{Os}$ respectively). On the other hand, the near range in the tissue is also observed. The only consideration is a longer half-life of about $25 \%$ which can even be an advantage for the import/export as well as more secure transportation to the remote centers.

Thus, according to the physical data ${ }^{191}$ Osphytate can be a suitable candidate for small size joint radiosynovectomy such as metacarpophalangeal, metatarsophalangeal, digital interphalangeal joints [1].

\section{Table 2}

The Physical Characters of Some Radionuclides Used in Various Joint Sizes for Radiosynovectomy

\begin{tabular}{cccccc}
\hline Radionuclide & Half life & $\begin{array}{c}\text { beta maximum } \\
\text { energy } \mathbf{( M e V})\end{array}$ & $\begin{array}{c}\text { Range in } \\
\text { tissue }(\mathbf{m m})\end{array}$ & Joint size & Ref \\
\hline Yttrium-90 & $64.1 \mathrm{~h}$ & 2.28 & 2.5 & Large & {$[10]$} \\
Rhenium-186 & $89.3 \mathrm{~h}$ & 1.077 & 4.5 & Medium & {$[11]$} \\
Erbium-169 & $9.5 \mathrm{~d}$ & 0.34 & 0.3 & Small & {$[12]$} \\
Osmium-191 & $15.4 \mathrm{~d}$ & 0.37 & 0.4 & Small * & {$[13]$}
\end{tabular}




\section{REFERENCES}

1. G. Clunie and M. Fischer, EANM procedure guidelines for radiosynovectomy, EJNMMI 30, pp. BP12-BP16, (2003).

2. M. Kropacek, et al., Preparation of Holmium-166 Labelled Macroaggregates for radionuclide synovectomy, Nucl Med Rev Cent East Eur 6, pp. 1-4, (2003).

3. Y. S. Suzuki, et al., Biodistribution and kinetics of holmium-166-chitosan complex (DW-166HC) in rats and mice, JNM 39, pp. 2161-2166, (1998).

4. E. W. Lee, et al., Yttrium-90 selective internal radiation therapy with glass microspheres for hepatocellular carcinoma: current and updated literature review, KJR 17, p. 472, (2016).

5. I. Ikeda, et al., "Evaluation of $99 \mathrm{mTc}$-phytate as radiopharmaceutical," Radioisotopes, 25, p. 651, (1976).

6. A.R. Jalilian, et al., Development of 166Ho-phytate Complex for Radiosynovectomy, NMMI 45, pp. 87-92, (2011).
7. H. Palmedo, et al., Painful Multifocal Arthritis: Therapy with Rhenium 186 Hydroxyethylidenediphosphonate (186Re HEDP) after Failed Treatment with Medication-Initial Results of a Prospective Study, Radiology 221, pp. 256-260, (2001).

8. C. Cheng, et al., A new osmium-191 leads to iridium-191m generator, JNM: official publication, Society of Nuclear Medicine, 21, p. 1169, (1980).

9. M. Jamre, et al., Development of an in vivo radionuclide generator by labeling bleomycin with 191 Os, JRNC 290, pp. 543-549, (2011).

10. C. Brihaye, et al., New osmium-191/iridium-191m radionuclide generator system using activated carbon, NMMI. (United States) 3, (1986).

11. M. IAEA-TECDOC, 1340. Manual for reactor produced radioisotope, Vienna: International Atomic Energy Agency, (2003).

12. K. Kairemo, et al., 191mIr: distribution and retention in animal experiments, Nuklearmedizin, 34, p. 115, (1995).

\section{How to cite this article}

Moghaddam et al., Preparation of 1910s-phytate, an in-vivo radionuclide generator, for radiosynovectomy application, Nuclear Engineering Progress 1 (1): 9-17 (2021), DOI: 10.24200/nep.2021.1001

(c) (1) This work is licensed under the Creative Commons Attribution 4.0 International License.

To view a copy of this license, visit http://creativecommons.org/licenses/by/4.0/. 